\title{
Adoptive T-cell therapy for hematological malignancies using $T$ cells gene-modified to express tumor antigen-specific receptors
}

\author{
Hiroshi Fujiwara
}

Received: 19 November 2013/Revised: 4 December 2013/Accepted: 4 December 2013/Published online: 19 December 2013

(c) The Japanese Society of Hematology 2013

\begin{abstract}
The functional properties of the adoptive immune response mediated by effector $\mathrm{T}$ lymphocytes are decisively regulated by their T-cell receptors (TCRs). Transfer of genes encoding target antigen-specific receptors enables polyclonal $\mathrm{T}$ cells to redirect toward cancer cells and virally infected cells expressing those defined antigens. Using this technology, a large population of redirected $\mathrm{T}$ cells displaying uniform therapeutic properties has been produced, powerfully advancing their clinical application as "cellular drugs" for adoptive immunotherapy against cancer. Clinically, anticancer adoptive immunotherapy using these genetically engineered $\mathrm{T}$ cells has an impressive and proven track record. Notable examples include the dramatic benefit of chimeric antigen receptor gene-modified $\mathrm{T}$ cells redirected towards B-cell lineage antigen CD19 in patients with chronic lymphocytic leukemia, and the impressive outcomes in the use of TCR gene-modified $\mathrm{T}$ cells redirected towards NY-ESO-1, a representative cancer-testis antigen, in patients with advanced melanoma and synovial cell sarcoma. In this review, we briefly overview the current status of this treatment option in the context of hematological malignancy, and discuss a number of challenges that still pose an obstacle to the full effectiveness of this strategy.
\end{abstract}

Keywords Adoptive immunotherapy - Gene-modified $\mathrm{T}$ cell $\cdot \mathrm{T}$-cell receptor . Chimeric antigen receptor . Hematological malignancy

H. Fujiwara $(\square)$

First Department of Internal Medicine, Ehime University

Hospital, Shitsukawa, Tōon, Ehime 791-0295, Japan

e-mail: yunarief@m.ehime-u.ac.jp

\section{Introduction}

The concept of therapeutically gene-modified $\mathrm{T}$ cells was originally developed as an alternative approach for naturally deriving effector $\mathrm{T}$ cells that would be specifically responsive to therapeutic targets. In this context, it first seems pertinent to overview currently available adoptive immunotherapies that employ non-gene-modified $\mathrm{T}$ cells.

First, donor lymphocyte infusion (DLI) for patients with leukemia relapse after allogeneic hematopoietic stem cell transplantation (allo-HSCT) is an established option [1], exploiting the "graft versus leukemia" (GvL) effect mediated by donor-derived T cells [2]. Given that allo-immunity directs ubiquitously expressed immunogenic major or minor histocompatibility antigens in normal non-hematopoietic tissues, the GvL effect that is dependent on alloimmunity is inevitably associated with damage to such normal tissues (graft vs. host disease, GVHD) [3]. As GVHD can be potentially life-threatening, separation of the GVL effect from GVHD still remains a major challenge [4]. To this end, the exploration of effective immunogenic antigens that can be selectively or abundantly expressed in leukemia cells, but not in normal tissues, has been pursued [5]. Most recently, beyond harnessing a single leukemia antigen, DLI using donor lymphocytes sensitized with multiple leukemia-associated antigens for the treatment or prevention of leukemia relapse after allo-HSCT is being considered in anticipation of an augmented leukemia-suppressive effect without exacerbation of GVHD [6].

Adoptive transfer of ex vivo-expanded tumor-infiltrating lymphocytes (TIL) has also been proven effective, notably in the treatment of advanced melanoma [7]. In combination with chemo-radiotherapeutic preconditioning, even patients with advanced melanoma presenting massive lesions have been treated successfully, thus highlighting 
the significance of lympho-depletive preconditioning in the context of anticancer adoptive immunotherapy [8].

The third successful example of this approach is the adoptive transfer of virus-specific $\mathrm{T}$ cells for treatment of refractory reactivation of latent viruses after allo-HSCT, such as recurrent cytomegalovirus (CMV) infection [9], Epstein-Barr Virus (EBV)-driven lymphoproliferation [10], and recurrent adenovirus infection [11]. Given that the recall responses mediated by healthy donor $\mathrm{T}$ cells towards viral antigens to which they have been previously exposed are readily inducible, infusion of a relatively small number of ex vivo antigen-sensitized $\mathrm{T}$ cells has been shown to be sufficient for treatment of CMV infection and EBV-related diseases in transplant patients [12].

As described above, adoptive therapy using non-genemodified T cells has been shown to be potentially effective, albeit on a limited basis currently. To achieve a better clinical outcome, several prerequisite conditions have become apparent: (a) choice of an optimal target antigen; (b) guaranteed uniformity of the quantity and quality of therapeutic $\mathrm{T}$ cells administered; and (c) tumor trafficking and in vivo persistence of infused $\mathrm{T}$ cells. Gene-modified T-cell-based adoptive immunotherapy would seem to satisfy all of these requirements [13].

\section{Overview of the current use of gene-modified $T$ cells for anticancer adoptive immunotherapy}

Apart from the production of ex vivo-expanded virusspecific $\mathrm{T}$ cells from asymptomatic donors suffering latent infection [9-12], guaranteeing the production of clinically effective therapeutic $\mathrm{T}$ cells with uniform quality and quantity still remains a challenge, and this is largely hampering the clinical application of this type of treatment. Even TIL therapy for melanoma poses the same dilemma. In more than half of all melanoma patients, preparation of sufficient numbers of therapeutic $\mathrm{T}$ cells has been unsuccessful [14].

To overcome this obstacle, techniques for genetic redirection of $\mathrm{T}$ cells towards predefined therapeutic antigens have been developed, and now have a proven track record. At present, either retro- or lentiviral transfer of chimeric antigen receptors (CARs) for which target recognition is dependent on a component of a monoclonal antibody or that of a T-cell receptor (TCR) has resulted in the successful production of sufficient numbers of therapeutic $\mathrm{T}$ cells retaining their specificity for the defined antigens [15]. Consequently, these genemodified $\mathrm{T}$ cells expressing CARs (CAR-T cells) or TCRs (TCR-T cells) are now being applied clinically as "cellular drugs" for anticancer adoptive immunotherapy. Figure 1 shows a scheme of adoptive immunotherapy using gene-modified $\mathrm{T}$ cells, and Fig. 2 shows the basic structures of TCR-T and CAR-T cells. The TCR-T cell, but not the CAR-T cell, requires a specific HLA molecule for recognition of the target epitope, which is processed endogenously and presented on the surface of cancer cells.

The therapeutic quality of these TCR-T cells is primarily dependent on the avidity of the gene-modified $\mathrm{T}$ cells. To create higher avidity, several strategies have been developed aimed at increasing the affinity of relevant TCR beyond that expressed by naturally occurring T cells in response to an identical epitope [16-18]. Such affinityincreased TCRs have already been employed in several clinical trials [19-21].

On the other hand, it is well known that introduction of therapeutic TCR can create unintended $\alpha / \beta$ heterodimers formed between introduced and endogenous TCR $\alpha / \beta$ chains (mispairing). Such mispairing can directly reduce the cell surface expression of the intended TCR$\alpha / \beta$ pairing, thus impairing the responsiveness of the gene-modified $\mathrm{T}$ cells to low concentrations of target epitopes. This in turn can reduce the avidity of therapeutic $\mathrm{T}$ cells to primary cancer cells, as the latter generally express low amounts of relevant epitope/HLA complex on the cell surface [22, 23]. Furthermore, the potential risk of autoimmune disease caused by newly generated mispaired TCR displaying unpredictable autoresponsiveness has recently been highlighted in a mouse model [24]. In order to inhibit such TCR mispairing, knockdown or knockout of endogenous $T C R-\alpha / \beta$ gene expression has recently been attempted using siRNA technology (siTCR vector) $[25,26]$ or zinc-finger nuclease (ZFN) technology [27, 28]. In cooperation with Takara Bio Inc. and Mie University, we have developed the siTCR vector system, and most recently have initiated a clinical trial using a therapeutic siTCR vector targeting Wilms Tumor 1 (WT1-siTCR vector) [29] for patients with acute myelogenous leukemia (AML) and myelodysplastic syndrome (MDS) (UMIN 0001159). However, development of ZFN technology is still at the preclinical stage.

The CAR construct is composed of an extracellular antigen-binding domain, a transmembrane domain, and a cytoplasmic signaling domain [30]. The majority of previous studies have focused on engineering the cytoplasmic domain to generate signals most appropriate for the activation of CAR-T cells in the anticipation of achieving better antitumor functionality. First-generation CAR constructs containing only CD3- $\zeta$ or FcR- $\gamma$ as cytoplasmic signaling molecules $[31,32]$ were unable to fully execute the anticipated antitumor effect [33]. Subsequent limitations in proliferative response, persistence and homing to local tumor tissues mediated by CAR-T 


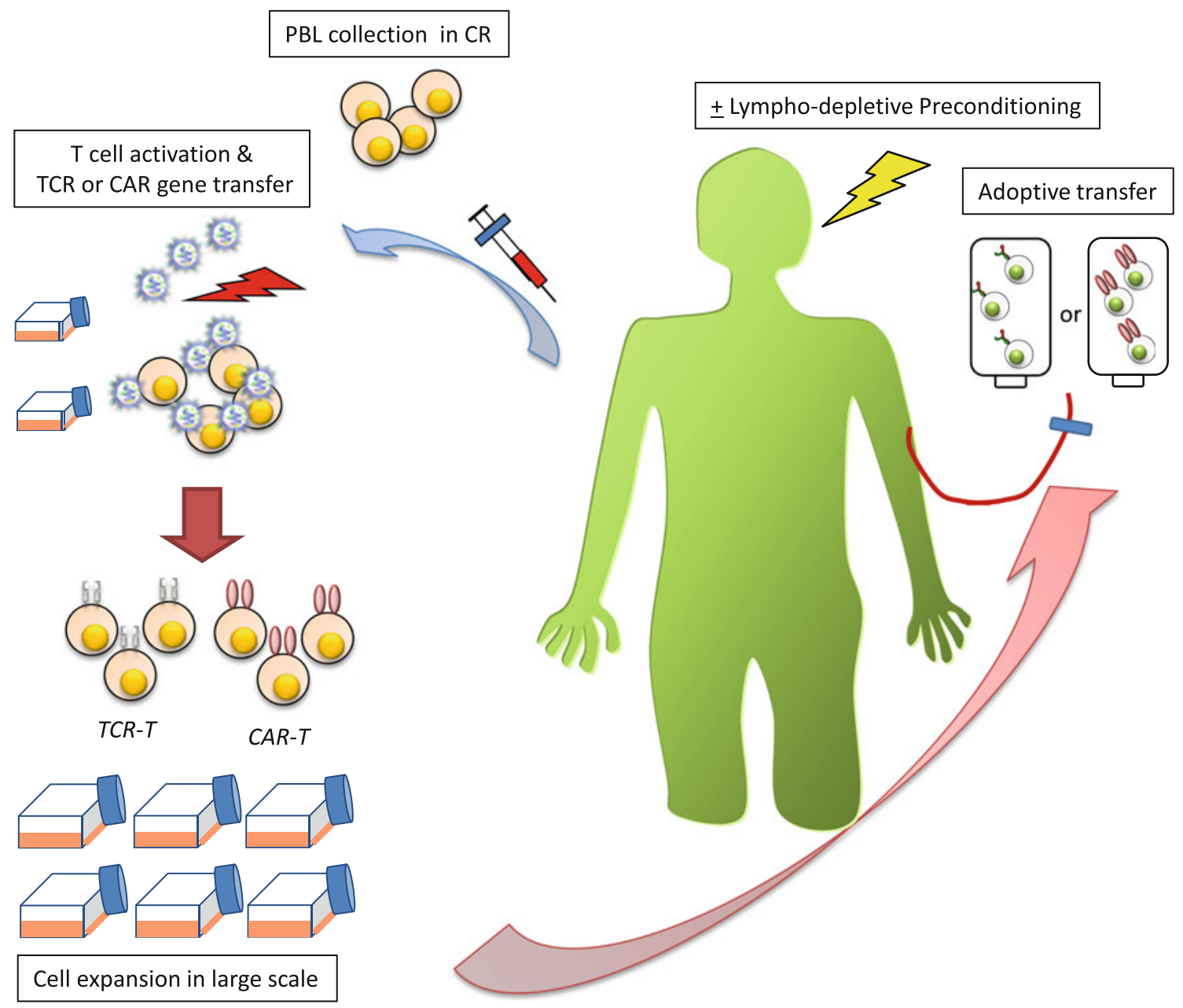

Fig. 1 Scheme of adoptive immunotherapy using gene-modified $\mathrm{T}$ cells. Ideally, PBL harvested from patients with leukemia in CR using leukapheresis are subjected to gene modification to express relevant TCR or CAR, and then expanded on a large scale using a cellprocessing center. A sufficient number of these gene-modified effector cells are then infused back into the same patients, with or without chemo-radiotherapeutic preconditioning. $P B L$ peripheral blood lymphocytes, $C R$ complete remission, $T C R$ T-cell receptor, $C A R$ chimeric antigen receptor, TCR-T T-cell receptor gene-transduced $\mathrm{T}$ cells, CAR-T chimeric antigen receptor gene-transduced $\mathrm{T}$ cells

\section{Results of clinical trials using engineered $T$ cells}

With regard to the treatment of hematological malignancies, promising outcomes have been achieved in clinical trials using CD19-specific CAR constructs for patients with B-cell lymphoma [44, 45, 47, 48], refractory chronic lymphocytic leukemia [42, 43, 46, 47], and acute lymphoblastic leukemia [46, 49]. Interestingly, more impressive clinical benefits were achieved using the CD19-CAR construct comprising $4.1 \mathrm{BB}$ in the signaling motif $[42,43$, 49] than with the use of CD28 [45, 46]. The mechanism underlying this difference in antitumor efficacy is intriguing, but not fully understood. Even if an "antigen with the same name" is targeted, the antitumor functionality displayed by CAR-T cells seems to differ according to the introduced individual CAR construct. As well as the 


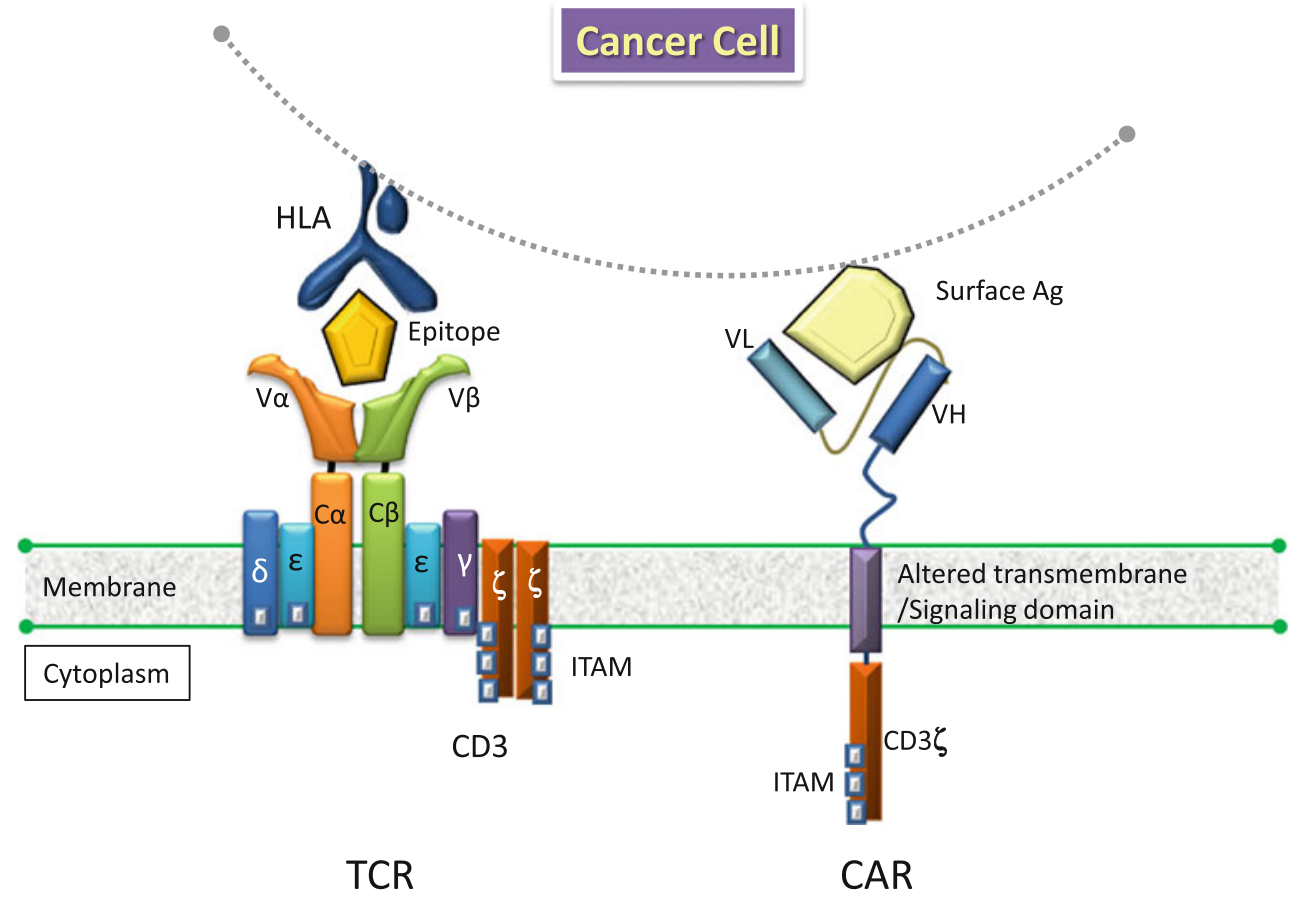

Gene-modified T cell

Fig. 2 Introduced TCR or CAR in a gene-modified T cell. Each construct of TCR (left) or CAR (right) in a gene-modified T cell is illustrated. TCR recognizes the epitope in the context of the specific HLA (left), whereas CAR recognizes the cell surface antigen based on the recognition machinery of a monoclonal antibody, independently of HLA (right). TCR T-cell receptor, CAR chimeric antigen receptor, $H L A$ human leukocyte antigen, $V \alpha$ variable region of the TCR

cytoplasmic domain, each CAR construct includes a different extracellular domain recognizing a different epitope of the same antigen with differing affinity [50]. However, the overall success of CAR-T cell therapy for B-cell malignancy seems largely attributable to the nature of CD19: (a) CD19 is expressed by not only leukemia cells, but also normal B cells including antigen-presenting B cells that can present co-stimulatory signals to CAR-T cells after contact, (b) leukemia cells are easily accessible to infused CAR-T cells within the same physiological compartment, and (c) apart from unknown late-phase adverse events, the adverse symptoms currently associated with B-cell depletion appear to be clinically manageable using intravenous administration of immunoglobulin. Thus, the importance of the chosen optimal target antigen for genemodified T-cell therapy is again emphasized by the successful use of anti-CD19 CAR-T cell therapy.

On the other hand, no clinical observations of TCR-T therapy for hematological malignancy have yet been reported. In this area, Rosenberg et al. have been playing a $\alpha$-chain, $V \beta$ variable region of the TCR $\beta$-chain, $C \alpha$ constant region of the TCR $\alpha$-chain, $C \beta$ constant region of the TCR $\beta$-chain, $\varepsilon, \gamma \delta$, $\zeta$ each subunit of the CD3 molecule, $A g$ antigen, $V L$ variable region of the immunoglobulin light chain, $V H$ variable region of the immunoglobulin heavy chain, ITAM immunoreceptor tyrosine-based activation motif

leading role, particularly with regard to the treatment of advanced melanoma [19, 51] and solid tumors [20]. Recently, the same group have reported impressive clinical outcomes with the use of high-affinity TCR specific to NYESO-1, a cancer-testis antigen (CTA) that is overexpressed in various kinds of cancers, but negligibly expressed in almost all normal tissues except for testis, which is an immunological sanctuary lacking any expression of HLA class I molecules [21]. Infused NY-ESO-1-specific TCR-T cells resulted in obvious tumor regression in patients with advanced melanoma and synovial cell carcinoma. In that study, employed HLA-A*0201-restricted NY-ESO-1-specific TCR was genetically mutated to upregulate the affinity. Videlicet, a TCR with unnaturally upregulated affinity, tends to damage normal tissues as an on-target adverse effect (AE), but not when NY-ESO-1 is targeted. Because of thymic selection during the development of $\mathrm{T}$ cells and the fact that a large proportion of tumor antigens are self-antigens, natural occurring TCRs displayed on circulating $\mathrm{T}$ cells generally express low affinity for self- 
antigens (Kd range 1-100 $\mu \mathrm{M}$ ), which makes such circulating $\mathrm{T}$ cells less responsive to cancer cells, because the latter generally tend to display small amounts of epitope/ HLA complexes on their surface [52]. Of necessity, this situation has motivated researchers to develop a technology for artificially upregulating the affinity of relevant TCR to a level as high as that of a monoclonal antibody ( $\mathrm{Kd}$ value $<\mathrm{nM}$ ). Consequently, as described above, emerging onand off-target adverse effects caused by these artificially high-affinity TCRs have become a serious issue, and were encountered only occasionally when naturally occurring TCRs were employed. Such adverse effects will be discussed in the next section.

In the context of hematological malignancy, two clinical trials of treatment for AML/MDS targeting WT1 are currently ongoing; one is being conducted by our group in Japan using a naturally occurring HLA-A*2402-restricted WT1-specific siTCR (UMIN000011519), and the other by Greenberg and colleagues in the USA using an affinityincreased HLA-A*0201-restricted WT1-specific TCR (NCT01640301, ClinicalTrials.gov). The latter group have recently reported results from a clinical trial using ex vivoexpanded CTL clones bearing the HLA-A*0201-restricted WT1 epitope for treatment of relapsed or high-risk AML after allo-HSCT [53], and instead of CTL clones they are employing gene-modified $\mathrm{T}$ cells expressing TCR specific for the same HLA-A*0201-restricted WT1 epitope in turn.

\section{Adverse effects impeding the efficacy of treatment with gene-modified $\mathbf{T}$ cells}

The AEs observed in the setting of adoptive therapy using gene-modified $\mathrm{T}$ cells can be broadly classified into three categories: (a) on-target $\mathrm{AE}$ due to the expression of target antigens in normal tissues and organs recognized by introduced CAR or TCR; (b) off-target AE damage to normal tissues and organs that do not express the target antigens recognized by the introduced CAR or TCR; (c) tissue damage due to lympho-depleting chemo-radiotherapeutic preconditioning.

Despite obvious tumor shrinkage, on-target AEs have been observed in a clinical trial using high-avidity murine or affinity-increased TCR specific for the melanoma-associated antigen MART-1 and gp100 in the context of HLA$A^{*} 0201$, which are also substantially expressed in normal melanocytes and pigmented tissues, resulting in skin rash, hearing loss, and uveitis [19]. Because carcinoembryonic antigen (CEA) is constitutively expressed by epithelia in the entire colon, another example of treatment-required $\mathrm{AE}$ is severe inflammatory colitis, which was observed in all of 3 colon cancer patients who were treated with T cells genemodified to express a high-avidity murine TCR specific for
CEA in the context of HLA-A*0201 [20]. Both of these two studies employed high-affinity TCRs targeting tumorassociated antigens that are physiologically expressed at a low level in normal tissues. As described in the previous section, increased affinity of therapeutic TCR is desirable for better anticancer functionality mediated by TCR-T cells [54]. Quite recently, however, it has been reported that $T$ cells gene-modified using ultra-high-affinity TCRs (Kd values $<\mathrm{nM}$ ) specific for MAGE-A3, a leading CTA, have caused fatal damage to vital organs, including the central nervous system (CNS) [55] and heart [56]. Although the causative mechanism has not been fully clarified, the fatal brain damage in the former study using HLA-A*0201restricted MAGE-A3-specific TCR was attributable to on-target AE against the epitopes derived from MAGE-A family proteins expressed at a low level in brain tissues, and the cardiac death in the latter study using HLA-A*01restricted MAGE-A3-specific TCR was attributable to offtarget $\mathrm{AE}$ against a similar epitope derived from the protein titin, a striated muscle protein constitutively expressed in cardiac muscle. The most important lesson from these cases is that such a serious $\mathrm{AE}$ was not predictable, despite intensive preclinical studies including murine systems. Accordingly, the authors of the latter report have proposed a novel screening system using a relevant HLA-expressing organ cell panel derived from induced pluripotent stem cells (iPSCs) to predict any risk of serious self-reactivity mediated by affinity-upregulated TCRs.

Elimination of the normal B-cell compartment in patients treated with CD19-CAR-T cells represents another on-target $\mathrm{AE}$ that is expected to be manageable using immunoglobulin replacement therapy $[42,45]$. Treatmentrequiring on-target $\mathrm{AE}$ is not necessarily limited to such ultra-high-affinity TCR-expressing TCR-T cells. A case of serious pulmonary failure ending in multi-organ failure due to a systemic cytokine storm has been reported in a patient with metastatic colon cancer who received CAR-T cells specific to human epithelial growth factor 2 (Her2, CD340) [57]. This Her2-specific CAR construct included CD28, $4-1 \mathrm{BB}$, and $\mathrm{CD} 3 \zeta$ in the cytoplasmic signaling motif, i.e. a "souped-up" CAR construct. In addition, this patient underwent lympho-depletive preconditioning. The authors of the latter report speculated that this serious event was probably triggered by broad low-level expression of Her2 in pulmonary epithelial cells.

Off-target $\mathrm{AE}$ is mainly characterized by tissue or organ damage resulting from therapy-induced massive release of inflammatory cytokines (a so-called cytokine storm). For example, cardiac toxicity described in a patient who had received CD19-CAR-T cells was not due to CD19 expression in heart tissue $[42,45]$. In the patients who manifested cardiac symptoms, elevated serum levels of inflammatory cytokines including IFN- $\gamma$, 
TNF- $\alpha$, and IL- 6 were observed. Another fatal cardiac off-target $\mathrm{AE}$ event occurred in a clinical trial using CAR-T cells specific for mesothelin. This toxic event was due to anaphylaxis mediated by human anti-mouse antibody formation against the murine component of the CAR construct [58]. Another major cause of serious offtarget AE is tumor lysis syndrome (TLS) associated with the rapid and massive destruction of tumor cells, which makes high treatment efficacy a double-edged sword. The pathophysiological features of TLS considerably overlap those of a cytokine storm [59]. A fatal complication of treatment with CD19-CAR-T cells has been reported in a patient who manifested increased serum levels of phosphorus, potassium and uric acid, being compatible with TLS. This complication was finally managed successfully by rearrangement of the CAR-T cell transfusion schedule [60].

\section{Future directions}

To date, improvements in anticancer functionality mediated by gene-modified $\mathrm{T}$ cells and development of lymphodepleting preconditioning now seem to largely satisfy the prerequisites for a better clinical outcome in patients receiving this treatment. However, there are still numerous unsolved issues before successful adoptive immunotherapy using gene-modified $\mathrm{T}$ cells can be established (Fig. 3).

Above all, to circumvent serious on-target AEs, an appropriate choice of antigen is indisputably important. The ideal target antigen should be selectively expressed in tumor cells, but absent in normal tissues, and sufficiently immunogenic to evoke T-cell responses, resulting in effective antitumor reactivity without damage to normal cells. Two types of antigen meet these requirements: (a) viral antigens in virus-induced tumors and (b) mutated

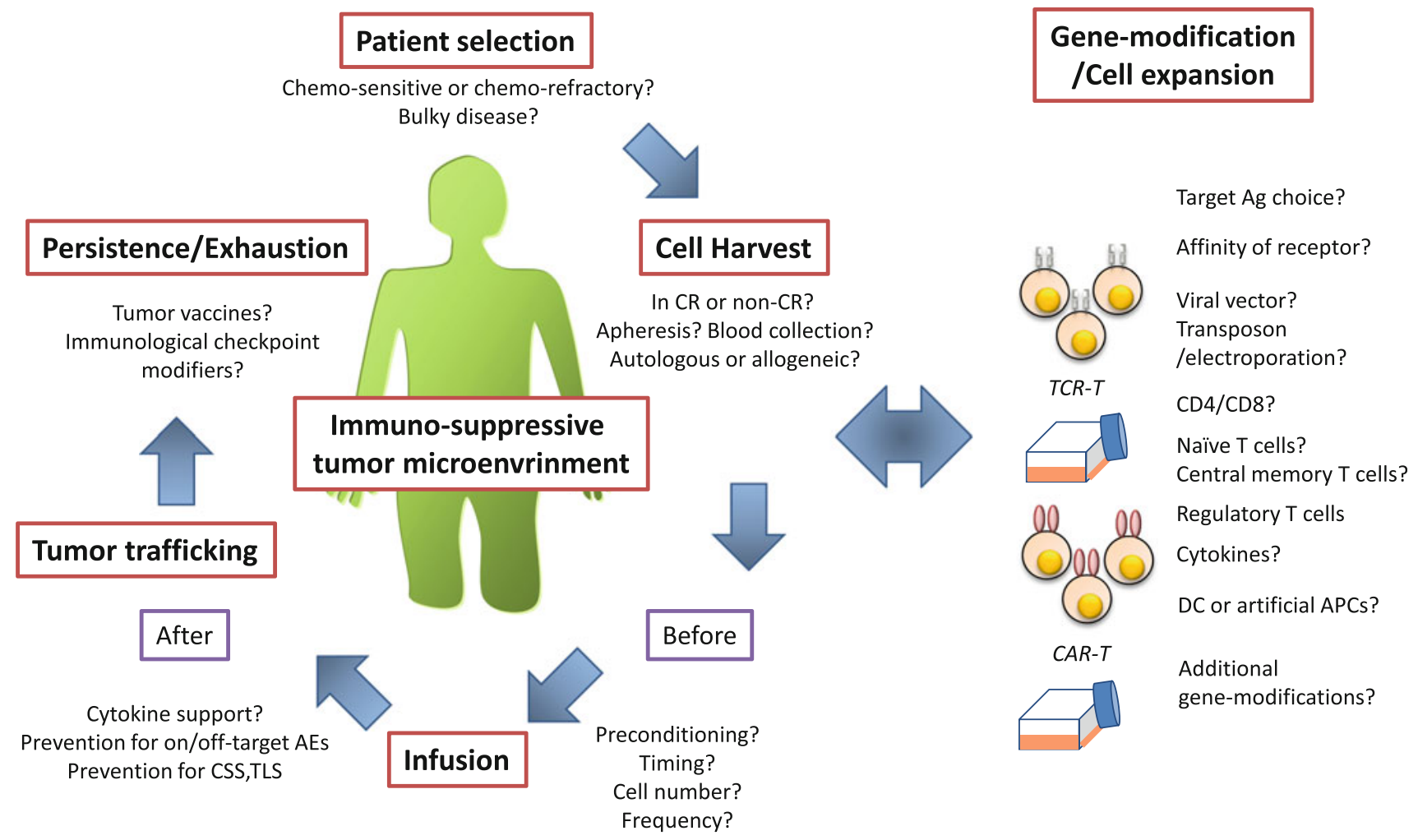

Fig. 3 Factors necessary for the establishment of successful adoptive immunotherapy using gene-modified $\mathrm{T}$ cells. In order to establish successful antileukemia adoptive immunotherapy using gene-modified $T$ cells, various factors still remain undetermined in the contexts of both T-cell manipulation in vitro (right) and the clinical setting (left). These factors will mutually interfere with each other and eventually determine the clinical outcome in any patient who receives this particular form of treatment. Factors coming under the heading of gene modification/cell expansion will impact on the quality and quantity of the gene-modified T-cell product. On the other hand, factors associated with the clinical setting are extremely variable; these would include how and when the T cells are harvested, how the gene-modified $\mathrm{T}$ cells are infused, i.e. with or without chemo- radiotherapeutic preconditioning, how unwanted CSS and TLS are avoided, how on- and off-target adverse effects are avoided, how the gene-modified $\mathrm{T}$ cells accumulate in local tumor tissues, and how the infused $\mathrm{T}$ cells are able to persist thereafter in vivo. Above all, it is important to consider how the known immunosuppressive tumor microenvironment should be overcome when adopting this type of immunotherapy. These issues need to be clarified in turn using welldesigned clinical trials, details of which are discussed in the Future Directions section. $A g$ antigen, $D C$ dendritic cells, $A P C$ antigenpresenting cells, TCR-T relevant TCR gene-modified T cells, CAR$T$ relevant $C A R$ gene-modified T cells, $C R$ complete remission, CSS cytokine storm syndrome, $T L S$ tumor lysis syndrome, $A E$ adverse effect 
antigens encoded in causative gene alterations in tumor cells. Although no therapeutic single epitope derived from antigens of infecting viruses has yet been successfully defined, it is anticipated that CAR-T cells or TCR-T cells, which are harnessed to the defined viral epitopes, will eliminate virus-transformed tumors. On the other hand, whole-exon sequencing of tumor cells has a proven track record for identifying novel candidate mutations in melanoma [63]. In terms of therapy for leukemia, identification of candidate mutations targeting leukemia stem cells may open a new avenue of immunotherapy in the near future $[64,65]$.

The search for more powerful antitumor efficacy has naturally prompted the artificial upregulation of therapeutic TCR affinity or target-responsive CAR functionality, both of which can overwhelmingly extend the functional range of naturally occurring T cells. Accordingly, serious off-target AEs due to incidental cross-reactivity that is difficult to control has emerged as an urgent issue. A series of iPS-origin vital-organ cell panels expressing common HLA haplotypes would seem advantageous for the prediction of such risks, which may not be fully predictable in silico [56].

On the other hand, a novel vector system that simultaneously encodes a suicide system has been developed to eliminate the unwanted toxicities mediated by infused gene-modified $\mathrm{T}$ cells [61]. Most recently, the caspase switch triggering apoptosis has been found to have clinical promise, allowing effective elimination of infused CAR-T cells and resolution of clinical symptoms in patients manifesting GVHD [62].

Finally, not only artificial receptor engineering, but also the features of the $\mathrm{T}$ cell itself as a target for gene modification have become important. To ensure the sufficient expansion and durable persistence in vivo of infused engineered $\mathrm{T}$ cells following contact with tumor cells, the advantage of naïve or central memory $\mathrm{T}$ cells as targets for gene modification has already been pointed out [66, 67]. Such elaborate usage of proper T-cell subsets for T-cell engineering might obviate the need for chemo-radiotherapeutic lympho-depleting preconditioning, which is associated with treatment-related toxicity. In addition to selection of T-cell subsets, in combination with agents for the blockade of immunological checkpoints, such as anti-cytotoxic T-lymphocyte-associated antigen (CTLA)-4 antibody [68], and anti-programmed cell death (PD)-1/PD-ligand 1 (PD-L1) antibody [69, 70], redirected T-cell-based adoptive immunotherapy might no longer require lympho-depleting preconditioning, because durably persisting $\mathrm{T}$ cells gene-modified to express melanoma-associated antigen-specific TCRs after therapeutic infusion have been shown to be sensitive to PD-L1/PD-1 interaction, as is the case in long-term retrovirus infection [71].

\section{Conclusion}

In the context of hematological malignancy, the final goal of redirected T-cell-based adoptive immunotherapy is to provide durable protective immunity against disease progression in patients without collateral damage to normal tissue, and so far this has been achieved successfully only for allo-HSCT. To this end, various sophisticated approaches are currently being tested, and in the near future adoptive immunotherapy using gene-modified $\mathrm{T}$ cells might be able to take the place of allo-HSCT for certain types of hematological malignancy.

Conflict of interest The author declares that I have no conflict of interest.

\section{References}

1. Kolb HJ, Schmid C, Barrett AJ, Schendel DJ. Graft-versus-leukemia reactions in allogeneic chimeras. Blood. 2004;103(3):767-76.

2. Miller JS, Warren EH, van den Brink MR, Ritz J, Shlomchik WD, Murphy WJ, et al. NCI first international workshop on the biology, prevention, and treatment of relapse after allogeneic hematopoietic stem cell transplantation: report from the committee on the biology underlying recurrence of malignant disease following allogeneic HSCT: graft-versus-tumor/leukemia reaction. Biol Blood Marrow Transpl. 2010;16:565-86.

3. Ferrara JL, Levine JE, Reddy P, Holler E. Graft-versus-host disease. Lancet. 2009;373:1550-61.

4. Warren EH, Fujii N, Akatsuka Y, Chaney CN, Mito JK, Loeb KR, et al. Therapy of relapsed leukemia after allogeneic hematopoietic cell transplantation with $\mathrm{T}$ cells specific for minor histocompatibility antigens. Blood. 2010;115:3869-78.

5. Vincent K, Roy DC, Perreault C. Next-generation leukemia immunotherapy. Blood. 2011;118:2951-9.

6. Weber G, Gerdemann U, Caruana I, Savoldo B, Hensel NF, Rabin KR, et al. Generation of multi-leukemia antigen-specific $\mathrm{T}$ cells to enhance the graft-versus-leukemia effect after allogeneic stem cell transplant. Leukemia. 2013;27:1538-47.

7. Rosenberg SA, Dudley ME. Adoptive cell therapy for the treatment of patients with metastatic melanoma. Curr Opin Immunol. 2009;21:233-40.

8. Dudley ME, Yang JC, Sherry R, Hughes MS, Royal R, Kammula $\mathrm{U}$, et al. Adoptive cell therapy for patients with metastatic melanoma: evaluation of intensive myeloablative chemoradiation preparative regimens. J Clin Oncol. 2008;26:5233-9.

9. Blyth E, Clancy L, Simms R, Ma CK, Burgess J, Deo S, et al. Donor-derived CMV-specific $\mathrm{T}$ cells reduce the requirement for CMV-directed pharmacotherapy after allogeneic stem cell transplantation. Blood. 2013;121:3745-58.

10. Doubrovina E, Oflaz-Sozmen B, Prockop SE, Kernan NA, Abramson S, Teruya-Feldstein J, et al. Adoptive immunotherapy with unselected or EBV-specific $\mathrm{T}$ cells for biopsy-proven $\mathrm{EBV}+$ lymphomas after allogeneic hematopoietic cell transplantation. Blood. 2012;119:2644-56.

11. Leen AM, Christin A, Myers GD, Liu H, Cruz CR, Hanley PJ, et al. Cytotoxic $\mathrm{T}$ lymphocyte therapy with donor $\mathrm{T}$ cells prevents and treats adenovirus and Epstein-Barr virus infections after haploidentical and matched unrelated stem cell transplantation. Blood. 2009;114:4283-92. 
12. Pagliara D, Savoldo B. Cytotoxic T lymphocytes for the treatment of viral infections and posttransplant lymphoproliferative disorders in transplant recipients. Curr Opin Infect Dis. 2012;25:431-7.

13. Ochi T, Fujiwara H, Yasukawa M. Requisite considerations for successful adoptive immunotherapy with engineered T-lymphocytes using tumor antigen-specific T-cell receptor gene transfer. Expert Opin Biol Ther. 2011;11:699-713.

14. Besser MJ, Shapira-Frommer R, Treves AJ, Zippel D, Itzhaki O, Schallmach E, et al. Minimally cultured or selected autologous tumor-infiltrating lymphocytes after a lympho-depleting chemotherapy regimen in metastatic melanoma patients. J Immunother. 2009;32:415-23.

15. Park TS, Rosenberg SA, Morgan RA. Treating cancer with genetically engineered $\mathrm{T}$ cells. Trends Biotechnol. 2011;29:550-7.

16. Li Y, Moysey R, Molloy PE, Vuidepot AL, Mahon T, Baston E, et al. Directed evolution of human T-cell receptors with picomolar affinities by phage display. Nat Biotechnol. 2005;23:349-54.

17. Stauss HJ. Immunotherapy with CTLs restricted by nonself MHC. Immunol Today. 1999;20:180-3.

18. Stanislawski T, Voss RH, Lotz C, Sadovnikova E, Willemsen RA, Kuball J, et al. Circumventing tolerance to a human MDM2derived tumor antigen by TCR gene transfer. Nat Immunol. 2001;2:962-70.

19. Johnson LA, Morgan RA, Dudley ME, Cassard L, Yang JC, Hughes MS, et al. Gene therapy with human and mouse T-cell receptors mediates cancer regression and targets normal tissues expressing cognate antigen. Blood. 2009;114:535-46.

20. Parkhurst MR, Yang JC, Langan RC, Dudley ME, Nathan DA, Feldman SA, et al. $\mathrm{T}$ cells targeting carcinoembryonic antigen can mediate regression of metastatic colorectal cancer but induce severe transient colitis. Mol Ther. 2011;19:620-6.

21. Robbins PF, Morgan RA, Feldman SA, Yang JC, Sherry RM, Dudley ME, et al. Tumor regression in patients with metastatic synovial cell sarcoma and melanoma using genetically engineered lymphocytes reactive with NY-ESO-1. J Clin Oncol. 2011;29:917-24.

22. Cohen CJ, Li YF, El-Gamil M, Robbins PF, Rosenberg SA, Morgan RA. Enhanced antitumor activity of T cells engineered to express T-cell receptors with a second disulfide bond. Cancer Res. 2007;67:3898-903.

23. Thomas S, Xue SA, Cesco-Gaspere M, San José E, Hart DP, Wong $\mathrm{V}$, et al. Targeting the Wilms tumor antigen 1 by TCR gene transfer: TCR variants improve tetramer binding but not the function of gene modified human $\mathrm{T}$ cells. $\mathrm{J}$ Immunol. 2007; 179:5803-10.

24. Bendle GM, Linnemann C, Hooijkaas AI, Bies L, de Witte MA, Jorritsma A, et al. Lethal graft-versus-host disease in mouse models of $\mathrm{T}$ cell receptor gene therapy. Nat Med. 2010;16:565-70.

25. Okamoto S, Mineno J, Ikeda H, Fujiwara H, Yasukawa M, Shiku $\mathrm{H}$, et al. Improved expression and reactivity of transduced tumorspecific TCRs in human lymphocytes by specific silencing of endogenous TCR. Cancer Res. 2009;69:9003-11.

26. Okamoto S, Amaishi Y, Goto Y, Ikeda H, Fujiwara H, Kuzushima $\mathrm{K}$, et al. A promising vector for TCR gene therapy: differential effect of siRNA, 2A peptide, and disulfide bond on the introduced TCR expression. Mol Ther Nucleic Acids. 2012;1:e63.

27. Provasi E, Genovese P, Lombardo A, Magnani Z, Liu PQ, Reik A, et al. Editing $T$ cell specificity towards leukemia by zinc finger nucleases and lentiviral gene transfer. Nat Med. 2012;18:807-15.

28. Torikai H, Reik A, Liu PQ, Zhou Y, Zhang L, Maiti S, et al. A foundation for universal $\mathrm{T}$-cell based immunotherapy: $\mathrm{T}$ cells engineered to express a CD19-specific chimeric-antigen-receptor and eliminate expression of endogenous TCR. Blood. 2012;119:5697-705.

29. Ochi T, Fujiwara H, Okamoto S, An J, Nagai K, Shirakata T, et al. Novel adoptive T-cell immunotherapy using a WT1-specific TCR vector encoding silencers for endogenous TCRs shows marked antileukemia reactivity and safety. Blood. 2011;118:1495-503.

30. Sadelain M, Brentjens R, Rivière I. The basic principles of chimeric antigen receptor design. Cancer Discov. 2013;3:388-98.

31. Irving BA, Weiss A. The cytoplasmic domain of the $\mathrm{T}$ cell receptor zeta chain is sufficient to couple to receptor-associated signal transduction pathways. Cell. 1991;64:891-901.

32. Eshhar Z, Waks T, Gross G, Schindler DG. Specific activation and targeting of cytotoxic lymphocytes through chimeric single chains consisting of antibody-binding domains and the gamma or zeta subunits of the immunoglobulin and T-cell receptors. Proc Natl Acad Sci USA. 1993;90:720-4.

33. Gong MC, Latouche JB, Krause A, Heston WD, Bander NH, Sadelain M. Cancer patient T cells genetically targeted to prostate-specific membrane antigen specifically lyse prostate cancer cells and release cytokines in response to prostate-specific membrane antigen. Neoplasia. 1999;1:123-7.

34. Haynes NM, Trapani JA, Teng MW, Jackson JT, Cerruti L, Jane $\mathrm{SM}$, et al. Rejection of syngeneic colon carcinoma by CTLs expressing single-chain antibody receptors codelivering CD28 costimulation. J Immunol. 2002;169:5780-6.

35. Carpenito C, Milone MC, Hassan R, Simonet JC, Lakhal M, Suhoski MM, et al. Control of large, established tumor xenografts with genetically retargeted human T cells containing CD28 and CD137 domains. Proc Natl Acad Sci USA. 2009;106(9):3360-5.

36. Hombach AA, Abken H. Costimulation by chimeric antigen receptors revisited the $\mathrm{T}$ cell antitumor response benefits from combined CD28-OX40 signalling. Int $\mathrm{J}$ Cancer. 2011;129:2935-44.

37. Finney HM, Akbar AN, Lawson AD. Activation of resting human primary $\mathrm{T}$ cells with chimeric receptors: costimulation from CD28, inducible costimulator, CD134, and CD137 in series with signals from the TCR zeta chain. J Immunol. 2004;172:104-13.

38. Finney HM, Lawson AD, Bebbington CR, Weir AN. Chimeric receptors providing both primary and costimulatory signaling in T cells from a single gene product. J Immunol. 1998;161:2791-7.

39. Hombach A, Wieczarkowiecz A, Marquardt T, Heuser C, Usai L, Pohl C, Seliger B, et al. Tumor-specific $\mathrm{T}$ cell activation by recombinant immunoreceptors: CD3 zeta signaling and CD28 costimulation are simultaneously required for efficient IL-2 secretion and can be integrated into one combined CD28/CD3 zeta signaling receptor molecule. J Immunol. 2001;167:6123-31.

40. Gilham DE, Debets R, Pule M, Hawkins RE, Abken H. T cells and solid tumors: tuning $\mathrm{T}$ cells to challenge an inveterate foe. Trends Mol Med. 2012;18:377-84.

41. Davila ML, Brentjens R, Wang X, Rivière I, Sadelain M. How do CARs work? early insights from recent clinical studies targeting CD19. Oncoimmunology. 2012;1:1577-83.

42. Kalos M, Levine BL, Porter DL, Katz S, Grupp SA, Bagg A, et al. $\mathrm{T}$ cells with chimeric antigen receptors have potent antitumor effects and can establish memory in patients with advanced leukemia. Sci Transl Med. 2011;3:95ra73.

43. Porter DL, Levine BL, Kalos M, Bagg A, June CH. Chimeric antigen receptor-modified $\mathrm{T}$ cells in chronic lymphoid leukemia. N Engl J Med. 2011;365(8):725-33.

44. Savoldo B, Ramos CA, Liu E, Mims MP, Keating MJ, Carrum G, et al. CD28 costimulation improves expansion and persistence of chimeric antigen receptor-modified T cells in lymphoma patients. J Clin Invest. 2011;121:1822-6.

45. Kochenderfer JN, Wilson WH, Janik JE, Dudley ME, StetlerStevenson M, Feldman SA, et al. Eradication of B-lineage cells 
and regression of lymphoma in a patient treated with autologous $\mathrm{T}$ cells genetically engineered to recognize CD19. Blood. 2010;116:4099-102.

46. Brentjens RJ, Rivière I, Park JH, Davila ML, Wang X, Stefanski J, et al. Safety and persistence of adoptively transferred autologous CD19-targeted T cells in patients with relapsed or chemotherapy refractory B-cell leukemias. Blood. 2011;118:4817-28.

47. Kochenderfer JN, Dudley ME, Feldman SA, Wilson WH, Spaner DE, Maric I, et al. B-cell depletion and remissions of malignancy along with cytokine-associated toxicity in a clinical trial of antiCD19 chimeric-antigen-receptor-transduced $\mathrm{T}$ cells. Blood. 2012;119:2709-20.

48. Jensen MC, Popplewell L, Cooper LJ, DiGiusto D, Kalos M, Ostberg JR, et al. Antitransgene rejection responses contribute to attenuated persistence of adoptively transferred CD20/CD19specific chimeric antigen receptor redirected $\mathrm{T}$ cells in humans. Biol Blood Marrow Transpl. 2010;16:1245-56.

49. Grupp SA, Kalos M, Barrett D, Aplenc R, Porter DL, Rheingold $\mathrm{SR}$, et al. Chimeric antigen receptor-modified $\mathrm{T}$ cells for acute lymphoid leukemia. N Engl J Med. 2013;368(16):1509-18.

50. Chmielewski M, Hombach A, Heuser C, Adams GP, Abken H. T cell activation by antibody-like immunoreceptors: increase in affinity of the single-chain fragment domain above threshold does not increase $\mathrm{T}$ cell activation against antigen-positive target cells but decreases selectivity. J Immunol. 2004;173:7647-53.

51. Morgan RA, Dudley ME, Wunderlich JR, Hughes MS, Yang JC, Sherry RM, et al. Cancer regression in patients after transfer of genetically engineered lymphocytes. Science. 2006;314:126-9.

52. Schmitt TM, Aggen DH, Stromnes IM, Dossett ML, Richman SA, Kranz DM, et al. Enhanced-affinity murine T-cell receptors for tumor/self-antigens can be safe in gene therapy despite surpassing the threshold for thymic selection. Blood. 2013;122:348-56.

53. Chapuis AG, Ragnarsson GB, Nguyen HN, Chaney CN, Pufnock JS, Schmitt TM, et al. Transferred WT1-reactive CD8+ T cells can mediate antileukemic activity and persist in post-transplant patients. Sci Transl Med. 2013;5:174ra27.

54. Valitutti S, Lanzavecchia A. Serial triggering of TCRs: a basis for the sensitivity and specificity of antigen recognition. Immunol Today. 1997;18:299-304.

55. Morgan RA, Chinnasamy N, Abate-Daga D, Gros A, Robbins PF, Zheng $\mathrm{Z}$, et al. Cancer regression and neurological toxicity following anti-MAGE-A3 TCR gene therapy. J Immunother. 2013;36:133-51.

56. Linette GP, Stadtmauer EA, Maus MV, Rapoport AP, Levine BL, Emery L, et al. Cardiovascular toxicity and titin cross-reactivity of affinity-enhanced T cells in myeloma and melanoma. Blood. 2013;122:863-71.

57. Morgan RA, Yang JC, Kitano M, Dudley ME, Laurencot CM, Rosenberg SA. Case report of a serious adverse event following the administration of $\mathrm{T}$ cells transduced with a chimeric antigen receptor recognizing ERBB2. Mol Ther. 2010;18:843-51.

58. Maus MV, Haas AR, Beatty GL, Albelda SM, Levine BL, Liu X, et al. $\mathrm{T}$ cells expressing chimeric antigen receptors can cause anaphylaxis in humans. Cancer Immunol Res. 2013;1:26. doi:10. 1158/2326-6066.CIR-13-0006.

59. Nakamura M, Oda S, Sadahiro T, Hirayama Y, Tateishi Y, Abe $\mathrm{R}$, et al. The role of hypercytokinemia in the pathophysiology of tumor lysis syndrome (TLS) and the treatment with continuous hemodiafiltration using a polymethylmethacrylate membrane hemofilter (PMMA-CHDF). Transfus Apher Sci. 2009;40:41-7.

60. Brentjens R, Yeh R, Bernal Y, Riviere I, Sadelain M. Treatment of chronic lymphocytic leukemia with genetically targeted autologous T cells: case report of an unforeseen adverse event in a phase I clinical trial. Mol Ther. 2010;18:666-8.

61. Ciceri F, Bonini C, Stanghellini MT, Bondanza A, Traversari C, Salomoni $\mathrm{M}$, et al. Infusion of suicide-gene-engineered donor lymphocytes after family haploidentical haematopoietic stem-cell transplantation for leukaemia (the TK007 trial): a non-randomised phase I-II study. Lancet Oncol. 2009;10:489-500.

62. Di Stasi A, Tey SK, Dotti G, Fujita Y, Kennedy-Nasser A, Martinez C, et al. Inducible apoptosis as a safety switch for adoptive cell therapy. N Engl J Med. 2011;365:1673-83.

63. Robbins PF, Lu YC, El-Gamil M, Li YF, Gross C, Gartner J, et al. Mining exomic sequencing data to identify mutated antigens recognized by adoptively transferred tumor-reactive T cells. Nat Med. 2013;19:747-52.

64. Snauwaert S, Vandekerckhove B, Kerre T. Can immunotherapy specifically target acute myeloid leukemic stem cells? Oncoimmunology. 2013;2(2):e22943.

65. Rohon P. Biological therapy and the immune system in patients with chronic myeloid leukemia. Int J Hematol. 2012;96(1):1-9.

66. Berger C, Jensen MC, Lansdorp PM, Gough M, Elliott C, Riddell $\mathrm{SR}$. Adoptive transfer of effector CD8+ $\mathrm{T}$ cells derived from central memory cells establishes persistent $\mathrm{T}$ cell memory in primates. J Clin Invest. 2008;118:294-305.

67. Hinrichs CS, Borman ZA, Cassard L, Gattinoni L, Spolski R, Yu $\mathrm{Z}$, et al. Adoptively transferred effector cells derived from naive rather than central memory $\mathrm{CD} 8+\mathrm{T}$ cells mediate superior antitumor immunity. Proc Natl Acad Sci USA. 2009;106:17469-74.

68. Hodi FS, O'Day SJ, McDermott DF, Weber RW, Sosman JA, Haanen JB, et al. Improved survival with ipilimumab in patients with metastatic melanoma. N Engl J Med. 2010;363:711-23.

69. Topalian SL, Hodi FS, Brahmer JR, Gettinger SN, Smith DC, McDermott DF, et al. Safety, activity, and immune correlates of anti-PD-1 antibody in cancer. N Engl J Med. 2012;366:2443-54.

70. Brahmer JR, Tykodi SS, Chow LQ, Hwu WJ, Topalian SL, Hwu $\mathrm{P}$, et al. Safety and activity of anti-PD-L1 antibody in patients with advanced cancer. N Engl J Med. 2012;366:2455-65.

71. Abate-Daga D, Hanada K, Davis JL, Yang JC, Rosenberg SA, Morgan RA. Expression profiling of TCR-engineered T cells demonstrates overexpression of multiple inhibitory receptors in persisting lymphocytes. Blood. 2013;122:1399-410. 